Vol. 17, No. 2 (April 2014)

\title{
AN INVESTIGATION OF THE FLOW OF WIND OVER A GROUP OF IDENTICAL PITCHED - ROOF BUILDING MODELS*
}

\author{
(Mofreh M. Nassief) \\ Faculty of Engineering, Zagazig University, Zagazig, Egypt \\ mofreh_melad@yahoo.com
}

\begin{abstract}
A wind-tunnel study and a numerical simulation were carried out on a group of four models representing identical pitched-roof buildings of low rise and aspect ratio $=1$. The simulation was carried out under the FLUENT Computational Fluid Dynamics (CFD) software package environment in which the boundary layer and the standard k- $\epsilon$ turbulence model are considered . The computed pressure coefficients were validated with results obtained for a 1:10 model in a wind tunnel. The effects of Reynolds number for wind directions of $0^{\circ}$ and $90^{\circ}$ and a roof angle of $45^{\circ}$ on pressure coefficient were investigated. The results indicate that the drag coefficient, hence the wind force, attains its highest value at $86 \%$ and $98 \%$ of building height for the upwind and downwind models, respectively. The results were compared with some experimentally-obtained wind tunnel results, showing fair- to- good agreements. The present study represents a contribution to the state of knowledge on the flow in the considered domain.
\end{abstract}

KEY WORDS: Pitched Roof, Low- Rise Buildings, Steady Incompressible Flows, Wind Load.

\section{UNE ENQUÊTE SUR LA CIRCULATION DE L'AIR SUR UN GROUPE D'IDENTIQUE PITCHED - TOIT CONSTRUCTION DE MODÈLES}

Une étude en soufflerie et la simulation numérique ont été effectués sur un groupe de quatre modèles représentant identiques bâtiments au toit en pente de faible hauteur et l'aspect ratio $=1$. La simulation a été effectuée dans la FLUENTE dynamique des fluides computationnelle (CFD) de l'environnement de logiciel dans laquelle la couche limite et le modèle de turbulence k- $\epsilon$ norme sont considérés. Les coefficients de pression calculés ont été validés avec les résultats obtenus pour un modèle à 1:10 dans une soufflerie. Les effets de nombre de Reynolds pour la direction du vent de $0^{\circ}$ et $90^{\circ}$ et un angle de toit de $45^{\circ}$ sur le coefficient de pression ont été étudiés. Les résultats indiquent que le coefficient de traînée, donc la force du vent, atteint sa valeur la plus élevée à 86 \% et 98 \% de la hauteur du bâtiment pour le vent et sous le vent modèles, respectivement. Les résultats ont été comparés avec des résultats en soufflerie expérimentale obtenus, montrant des accords équitables à bien. La présente étude constitue une contribution à l'état des connaissances sur l'écoulement dans le domaine considéré.

MOTS CLÉS: Toit En Pente, Les Bâtiments De Faible Hauteur, Les Ecoulements Incompressibles Stables , La Charge Du Vent .

* Received: 27/1/2014, accepted: 9/3/2014, Ref. No. 176, (Original Paper) 


\section{INTRODUCTION}

Building designers usually refer to codes of practice to determine wind loads on buildings. These codes are usually based on measurements in boundary layer wind tunnels. However, several building configurations are not covered by these codes. One such configuration is the pitched - roof building which has become common in building practice. Therefore, additional wind-tunnel measurements and numerical simulations are required to determine wind loads for such cases. Wind-tunnel tests are often laborious, time-consuming and costly, besides it is not practical to carry out tests on a prototype to determine the wind load. It may also be difficult to simulate the atmospheric turbulence properties and boundary layer for complex terrains. Numerical prediction of wind loads offers certain advantages over the use of scale models in boundary layer wind tunnels. For example, any Reynolds number, turbulence and boundary layer profile can be simulated. It is also convenient to carry out parametric studies with a numerical procedure, as the boundary conditions can be changed at ease. Numerical simulations therefore hold great potential for extending codes of practice. The accuracy of predictions depends primarily on proper choice of the boundary conditions, accuracy of discretization methods and most important on proper choice of turbulence model. In the following paragraphs, previous works pertinent to the case of pitched-roof buildings, the case of our concern here, and obstacles in general will be given in brief.

Lakehal and Rodi $^{3}$ (1997) calculated the steady flow past a surface-mounted cube with two-layer turbulence models. In their 3-D calculation, various versions of the $k-\varepsilon$ model were tested. They concluded that models using wall function cannot reproduce details of the complex flow structure near ground, e.g. the convergingdiverging behavior of the horse-shoe vortex. Late separation of the boundary layer ahead of the obstacle is produced in this case.

Murakami et al. ${ }^{4}$ (1997) worked on a CFD analysis of wind/structure interaction in case of oscillating square cylinders. They dealt with the flow field around oscillating square cylinders in case of forced oscillation as well as windinduced free oscillation. They showed that the rapid increase of the cylinder displacement is due to the increase of the reduced velocity for the case of wind- induced free oscillation.

Markham et al. ${ }^{5}$ (1999) carried out a CFD analysis of turbulent flow past a square cylinder using the LES (Large Eddy Simulation) technique. They concluded that the Lagrangian Dynamic Smagorinsky model (LDS model) is suitable to overcome the disadvantages of Dynamic Smagorinsky model, e.g. calculation instability.

Nozawa and Tamura ${ }^{6}$ (2002) validated the LES technique for predicting a flow around an obstacle under the condition that a turbulent flow is approaching the obstacle. The turbulent inflow data were generated for both a smooth surface and rough surface. They concluded that the peak pressure coefficients are underestimated when compared to full scale data.

Ginger and Holmes ${ }^{10}$ (2003) carried out a wind tunnel model study on a typical steep pitchgable roof storage building over a range of aspect ratios. Comparison was made of critical bending moments and the effective static pressure coefficients producing these bending moments with corresponding values obtained from the Australian Standard in addition to other major wind loading Standards. They showed that the 


\section{EIJEST}

effect of increasing length has much less influence on buildings with lower pitch angle (i.e. $15^{\circ}$ ) compared with planar roof and curved roof shapes.

Gao and Chow ${ }^{7}$ (2005) studied the air approach flow moving towards a cube using computational fluid dynamics. They concluded that by limiting the longitudinal velocities in the first cell adjacent to the sharp edge of the cube and making good use of the wall functions at the intersection cells of the velocity components, positions of maximum turbulent kinetic energy and the flow separation and reattachment can be predicated by standard k-e model.

Anne et al. ${ }^{1}$ (2005) carried out measurements of extreme environmental loading, demonstrating the potential for significant statistical deviation from the Gaussian assumption. In case of wind loads in separation zones, deviation from an assumed Gaussian distribution can have a dramatic effect on the peak values impinging upon structural components. They concluded thatwinds are found to produce high magnitudes of correlation on the roof surface of steeply sloped roofs and small regions of high correlation on the windward portion of lowsloped roofs.

Huang et al. ${ }^{8}$ (2007) conducted a comprehensive numerical study of wind effects on the Commonwealth Advisory Aeronautical Council (CAARC) Standard for tall buildings. The techniques of CFD, such as LES, RANS model etc., were adopted in this study to predict wind loads and wind flows around the building. They concluded that the velocity profile of the approaching wind flow mainly influences the mean pressure coefficients on the building and the incident turbulence intensity profile has a significant effect on the fluctuating wind forces.
Wael $^{9}$ (2009) predicted numerically and experimentally the effect of wind load on four different models of buildings. For commercial buildings, also artificial neural networks were used to predict the values of local load coefficient using "MATLAB 6.5" software. He concluded that the wake length behind the building model, for all the studied cases, decreases with height to reach minimum value at $\mathrm{Z} / \mathrm{H}=0.98$

Zaheer et al. ${ }^{2}$ (2011), in his review, showed that many researchers made significant contributions in the field of computational wind engineering in the last few decades. They concluded that the discrepancies in the pressure coefficient variations of TTU building model with wind tunnel testing results are due to the improper simulation in 2-D.

Kopp $^{11}$ (2014) tested scale models in a boundary layer wind tunnel and examined the effects of building size and array geometry on enveloping curves of area-averaged pressure coefficients. He concluded that for tilt angles less than $10^{\circ}$ the increase in the pressure coefficients as the tilt angle increases is approximately linear.

Previous work summarized here shows that there is still a room for more contributions to the state of knowledge in the field. One important area is perhaps the case of double- slanted (pitched) roof buildings, being which a common building practice in many parts of the world.

This paper demonstrates the effects of Reynolds number and wind direction $\left(0^{\circ}\right.$ and $\left.90^{\circ}\right)$ on the pressure coefficient for a group of four identical pitched-roof building with a roof angle of $45^{\circ}$. A finite-volume-based CFD procedure was applied through the well-known FLUENT commercial software package. Also, some experiments were 
carried out in an attempt to verify the numerical results obtained.

\section{NUMERICAL TREATMENT}

\subsection{Governing Equations and Boundary Conditions}

The air - flow pattern (velocity and pressure distribution) around a group of four models of identical and equi-distant pitched-roof low-rise buildings of aspect ratio=1 (length / span) will be predicated. The group is assumed to be sited on an area nine times the area of one building base area (Fig. (1)). The task of predication requires the development and application of a CFD-based computational procedure. In this respect, FLUENT is a well-known a computer package that is used to predict the airflow patterns (pressure and velocity contours) around arbitrary bodies. The procedure solves the standard continuity and momentum equations for threedimensional flows, based on the finite-volume approach combined with a k-€ turbulence model.
In the present work, the boundary conditions stipulate no slip and no penetration, i.e. the flow velocity at all solid surfaces is zero (satisfying the viscous fluid assumption), as shown in Fig.

(2). Also, basic assumptions include:

(i) fluid is Newtonian

(ii)approach velocity is uniform

(iii) flow is single phase, steady and incompressible

(iv) solution domain is of fixed geometry

(v) body forces are negligible

The above assumptions lead to the well-known standard governing equations (continuity and momentum equations) for 3-D steady incompressible flow. Solution of these equations requires use of a suitable turbulence model. The standard k- $\epsilon$ model was adopted in the present work and is described by the k- $\epsilon$ equation (1), coupled with the dissipation rate equation rate equation (2).

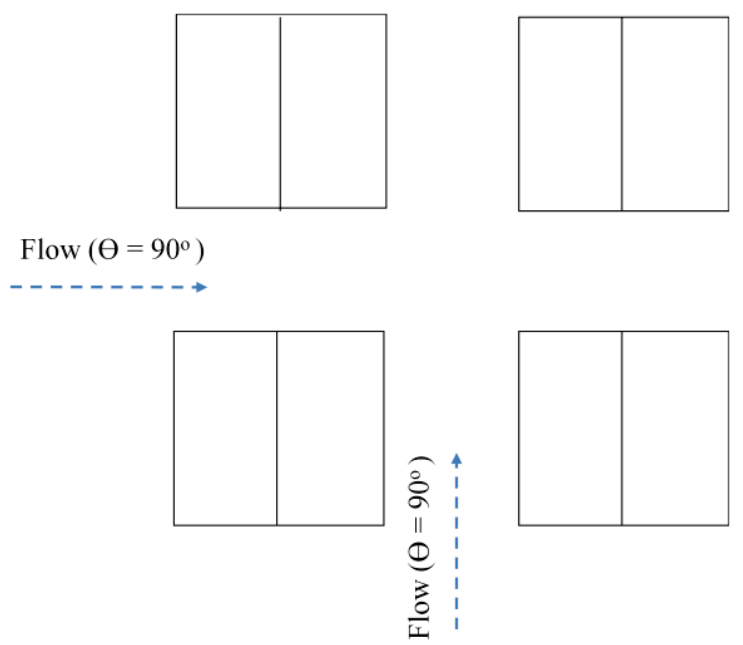

Case (2)

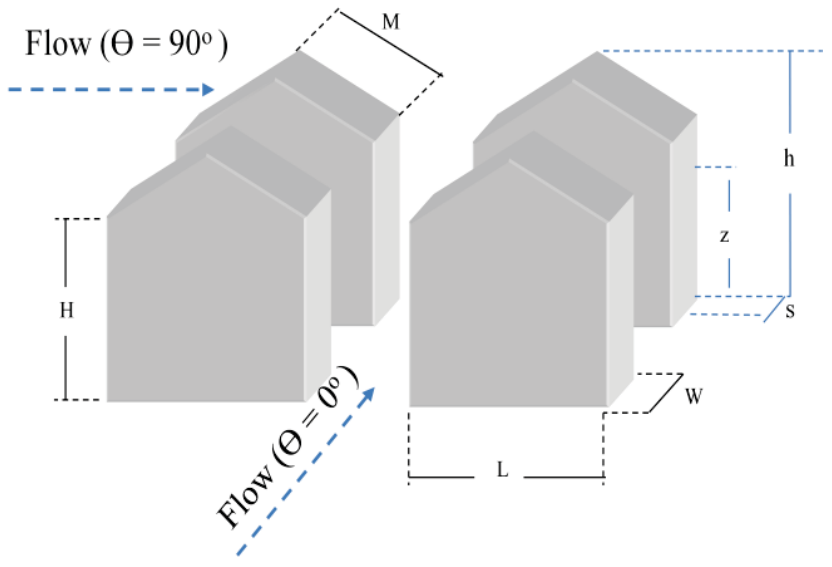

Case (1)

Top View $\mathrm{L}_{\mathrm{v}}=\mathrm{L}+2 \mathrm{H}+2 \mathrm{M} \quad \mathrm{L}_{\mathrm{h}}=2 \mathrm{~L}+2 \mathrm{~W}$

Fig. (1): Schematic diagram of tested models. 
Vol. 17, No. 2 (April 2014)

EIJEST

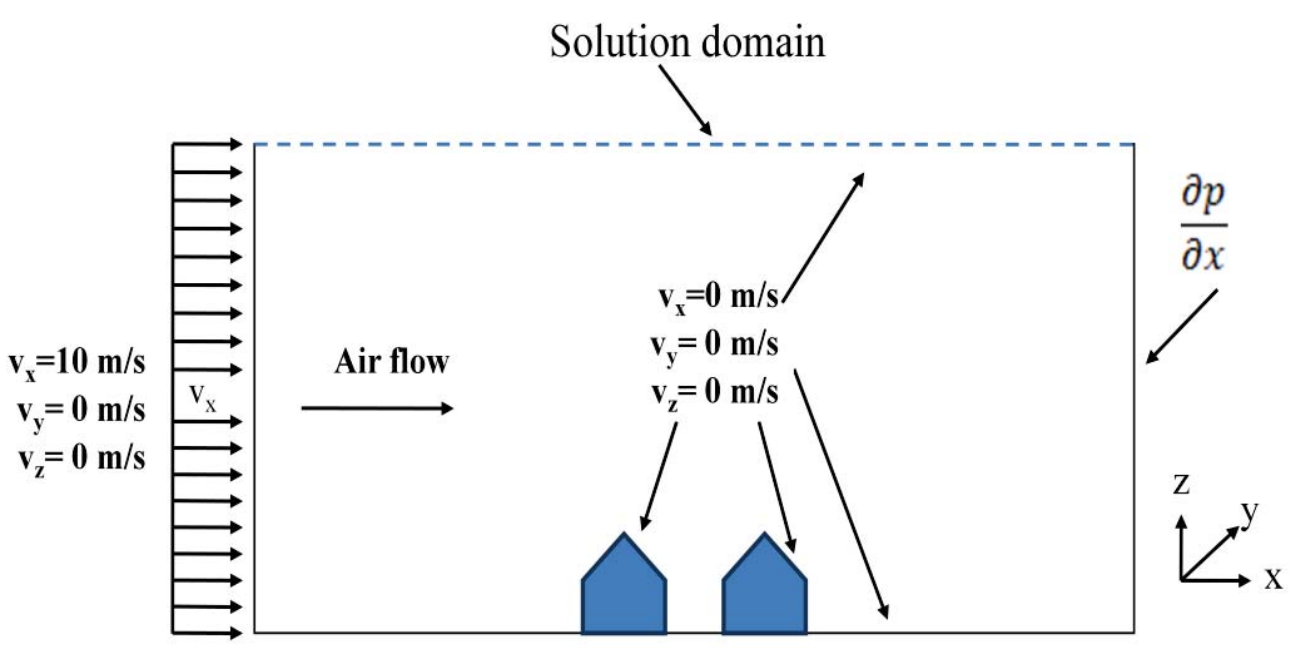

Fig. (2): Boundary conditions and solution domain.

$\rho \partial_{i} \quad U_{i}=\partial_{j}\left[\left(\mu+\frac{v_{t}}{\sigma_{k}}\right) \partial_{j}\right]+\mathrm{G}_{\mathrm{k}}-\rho \varepsilon$

(Turbulence equation)

$\rho \partial_{i} U_{i}=\partial_{j}\left[\left(\mu+\frac{v_{t}}{\sigma}\right) \partial_{j}+\mathrm{C}_{1 \varepsilon} \frac{\varepsilon}{\mathrm{k}} \mathrm{G}_{\mathrm{k}}-\mathrm{C}_{2 \varepsilon} \rho \frac{\varepsilon^{2}}{\mathrm{k}}\right]$

(Dissipation rate equation)

where, $\mu_{t}=C_{\mu} \rho \frac{k^{2}}{}, G_{k}=\overline{-\rho u_{i}^{\prime} u_{j}^{\prime}} \partial_{i}\left(U_{j}\right)$

Table (1) gives numerical values of the k-€ model coefficients in equation (2) above.

Table (1) : k- $\varepsilon$ model coefficients

\begin{tabular}{|c|l|l|l|l|}
\hline$C_{\mu}$ & $\sigma_{k}$ & $\sigma_{\varepsilon}$ & $C_{\varepsilon 1}$ & $C_{\varepsilon 2}$ \\
\hline 0.09 & 1.0 & 1.3 & 1.44 & 1.92 \\
\hline
\end{tabular}

\subsection{Grid Generation and Wall Treatment}

FLUENT is a software package that follows an iterative procedure in which a computational grid is generated and continually refined until the solution is grid-independent. Convergence of the numerical solution is thus attained through application of certain criteria. . Also, the law of the wall is embedded in the solution procedure as a chosen wall treatment. Fig. (3) shows a flow chart for the FLUENT software package and Fig. (4) shows a typical grid obtained through the computational process.

\section{EXPERIMENTAL TREATMENT}

The experimental work falls in two parts: flow visualization for the pitched- roof buildings by the smoke technique (fig. (5-a) shows a photo of the smoke tunnel used and fig. (5-b) shows the schematization of tested structures and visualization system). The second part is the pressure measurement all around the building surfaces. Therefore, four models of buildings were constructed (with length $=10 \mathrm{~cm}$, width $=10 \mathrm{cmand}$ height $=10 \mathrm{~cm}$ with pitched roof angle $=45^{\circ}$ ) from Plexiglas and tested in a suction type wind tunnel as shown in Fig. (6). The tests were carried out for the four buildings at $\mathrm{Re}=65799$.

\section{RESULTS AND DISCUSSIONS}

Table (2) gives the cases studied experimentally and numerically in the present work (case (1) and case (2) shown in Fig. (1)). 

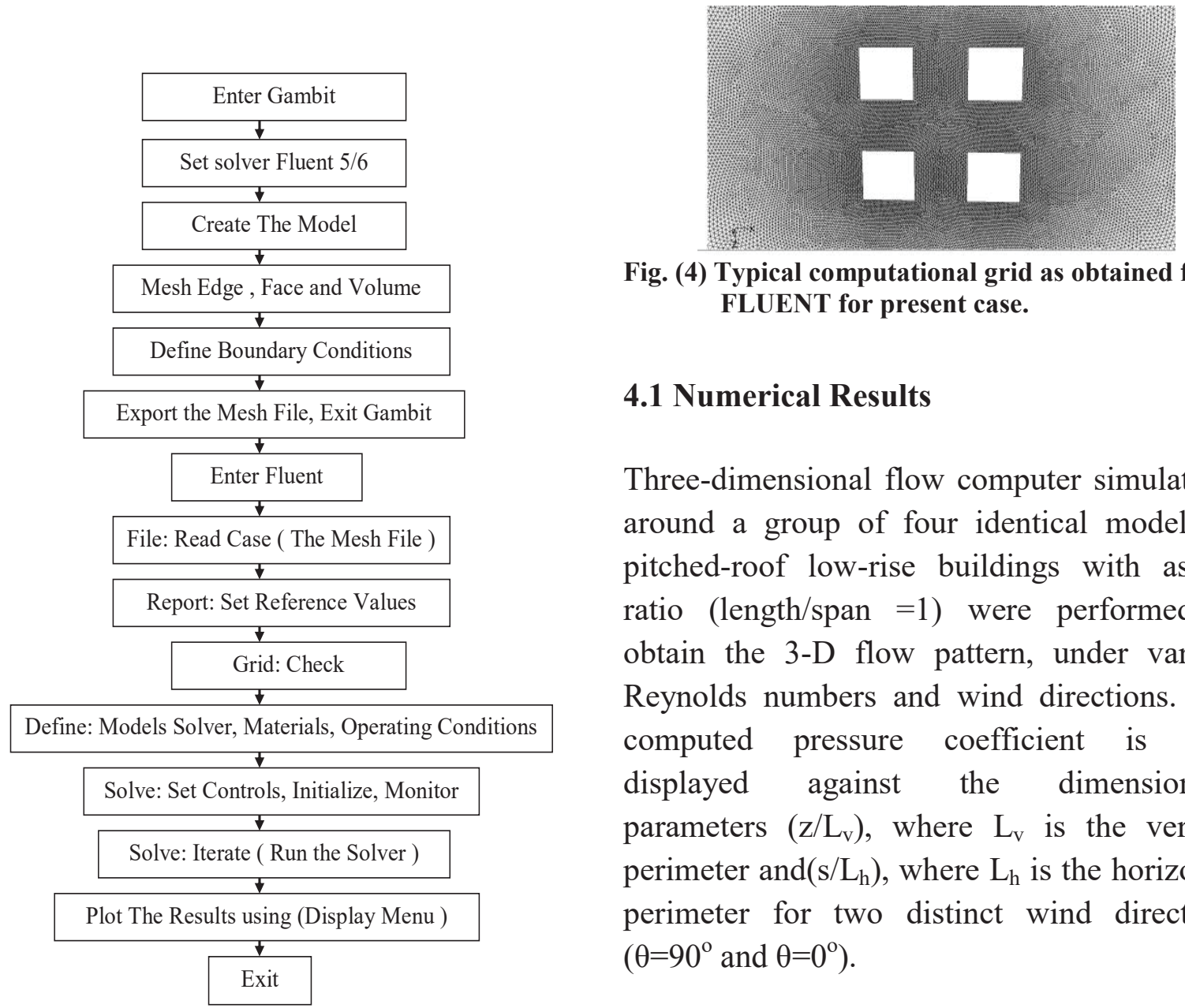

Fig. (4) Typical computational grid as obtained from FLUENT for present case.

\subsection{Numerical Results}

Three-dimensional flow computer simulations around a group of four identical models of pitched-roof low-rise buildings with aspect ratio (length/span $=1$ ) were performed to obtain the 3-D flow pattern, under various Reynolds numbers and wind directions. The computed pressure coefficient is here displayed against the dimensionless parameters $\left(\mathrm{z} / \mathrm{L}_{\mathrm{v}}\right)$, where $\mathrm{L}_{\mathrm{v}}$ is the vertical perimeter and $\left(\mathrm{s} / \mathrm{L}_{\mathrm{h}}\right)$, where $\mathrm{L}_{\mathrm{h}}$ is the horizontal perimeter for two distinct wind directions $\left(\theta=90^{\circ}\right.$ and $\left.\theta=0^{\circ}\right)$.

Fig. (3): FLUENT flow chart.

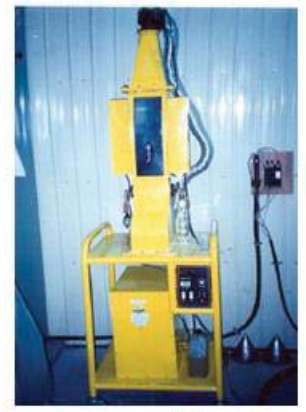

(a)

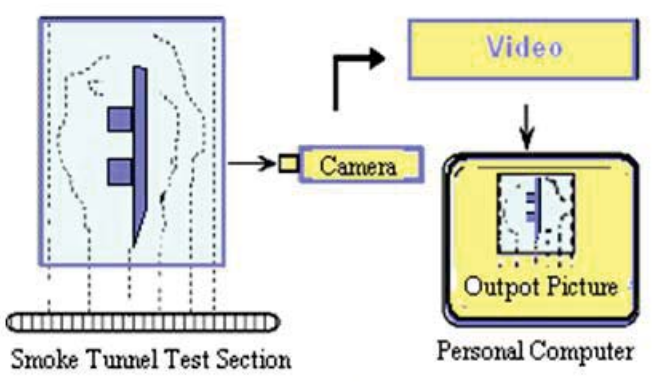

(b)

Fig. (5): (a) Photo of smoke tunnel, (b) Schematization of tested structures, and visualization system. 
Front View
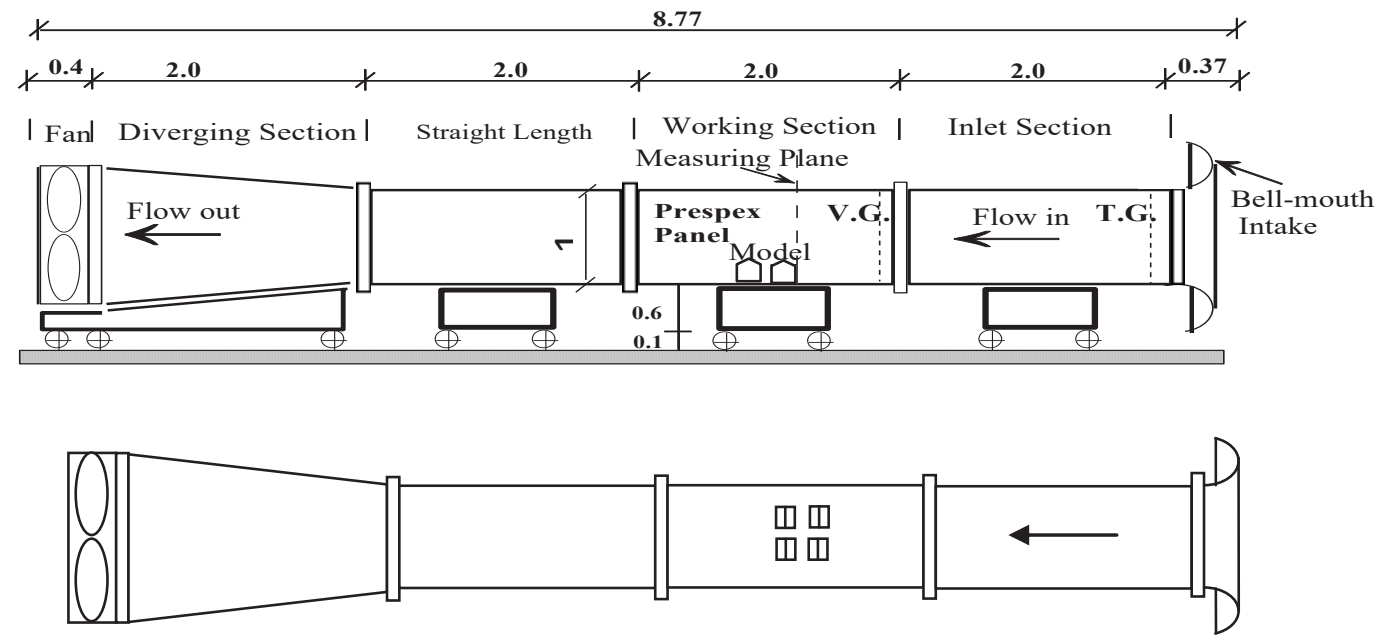

Top View

T.G.: Turbulence Grid, V.G.: Velocity Grid

Fig. (6): Schematic diagram of wind tunnel details. (dims. in m).

Table (2): Experimental and numerical study cases.

\begin{tabular}{|c|c|c|c|c|}
\hline Case & $\begin{array}{c}\text { Wind } \\
\text { direction } \\
\text { angle } \\
(\theta)\end{array}$ & Experimental & Numerical & $\begin{array}{c}\text { Reynolds } \\
\text { number, } \\
(\text { Re })\end{array}$ \\
\hline 1 & \multirow{2}{*}{$0^{\circ}$} & $\mathrm{X}$ & $\sqrt{ }$ & 46059 \\
\cline { 3 - 5 } & & $\sqrt{ }$ & $\sqrt{ }$ & 65799 \\
\cline { 3 - 5 } & & $\mathrm{X}$ & $\sqrt{ }$ & 131597 \\
\hline 2 & $90^{\circ}$ & $\sqrt{ }$ & $\sqrt{ }$ & 65799 \\
\hline
\end{tabular}

\subsubsection{Wind direction angle $=0^{\circ}$ (parallel to the roof crest line)}

Figure (7) shows pressure contours obtained for this case at $\mathrm{Re}=46059$, where the symmetry property flow configuration of the LHS and RHS buildings. The highest wind force is at approximately $86 \%$ of the height of the upwind building and $98 \%$ of the height of the downwind building. Fig. (8) shows the pressure coefficient contours at different planes at three different ( $R e=46059,65799$ and 131597). Here, we note that as $\mathrm{Re}$ increases the wind force increases, and the symmetry property remains at all planes. For all Re, the highest $\mathrm{C}_{\mathrm{p}}$ values occur at the higher planes.

Figure (9) shows $C_{p}$ distribution along the mid horizontal plane $\left(\mathrm{C}_{\mathrm{p}}\right.$ vs. $\left.\mathrm{s} / \mathrm{L}_{\mathrm{h}}\right)$, starting from the front stagnation point and ending with the same point, for the two upwind building models. The graphs show the symmetry of flow. Also the highest value of the pressure occurs at the stagnation point then the pressure decreases to its lowest value at $\mathrm{s} / \mathrm{L}_{\mathrm{h}}=0.15$, and then rises to a maximum at $\mathrm{s} / \mathrm{L}_{\mathrm{h}}=0.5$. The second half of the graph is a mirror image of the first half (symmetry property). 
Figure (10) shows the distribution of the local drag coefficient $\left(\mathrm{C}_{\mathrm{D}}\right)$ at different heights $\left(C_{D}\right.$ vs. $\left.z / h\right)$ for the upwind LHS and RHS building models at different Re. The drag coefficient increases (and so the wind force) with $(\mathrm{z} / \mathrm{h})$ to a maximum when $\mathrm{z} / \mathrm{h}$ is about 0.86 . Also the symmetry property prevails at all Re.

Figure (11) shows streamline patterns at different heights $(\mathrm{z} / \mathrm{h})$ and Re. The recirculation zone size decreases gradually for all cases with $\mathrm{z} / \mathrm{h}$ to a minimum size on the roof of the building. The maximum and the minimum size of the recirculation zone is found to occur at $\mathrm{z} / \mathrm{h}=0.25$ and 0.84 , respectively. For all cases the downwind building is entirely contained in the wake of the upwind building.

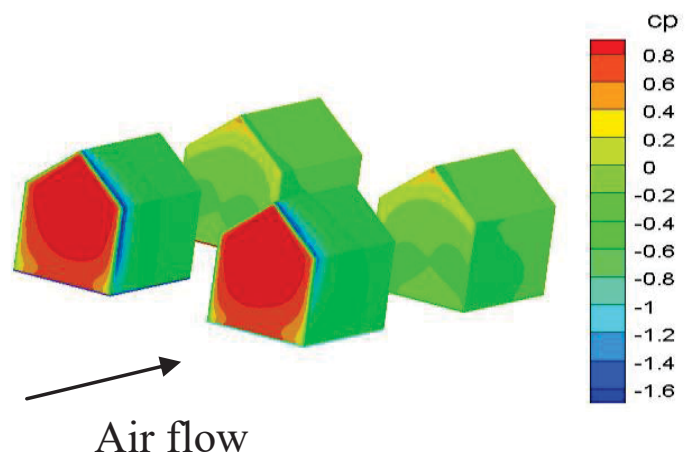

Fig. (7): Pressure coefficient contours $C_{p}$ of the four models, $R e=46059$

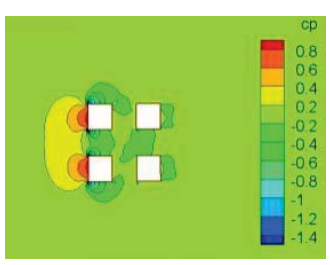

$\mathrm{z} / \mathrm{h}=0.25$
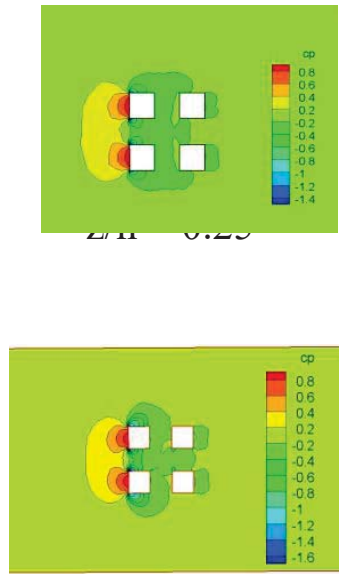

$\mathrm{z} / \mathrm{h}=0.25$

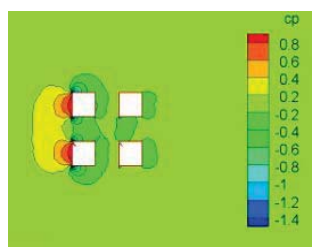

$\mathrm{z} / \mathrm{h}=0.5$

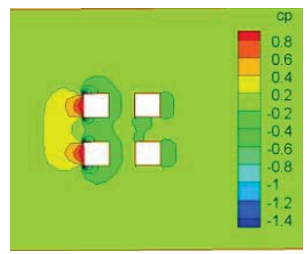

$\mathrm{z} / \mathrm{h}=0.67$

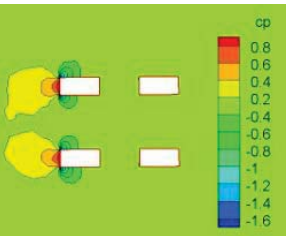

$\mathrm{z} / \mathrm{h}=0.84$

a) $\operatorname{Re}=46059$

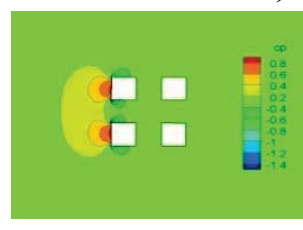

$\mathrm{z} / \mathrm{h}=0.5$

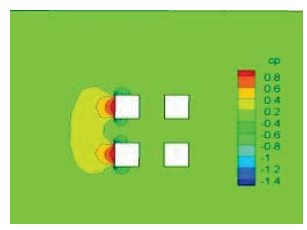

$\mathrm{z} / \mathrm{h}=0.67$

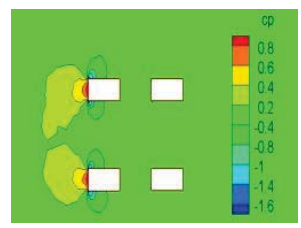

$\mathrm{z} / \mathrm{h}=0.84$

b) $\operatorname{Re}=65799$

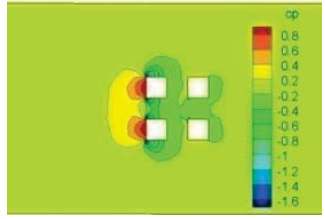

$\mathrm{z} / \mathrm{h}=0.5$

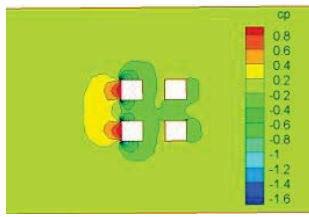

$\mathrm{z} / \mathrm{h}=0.67$

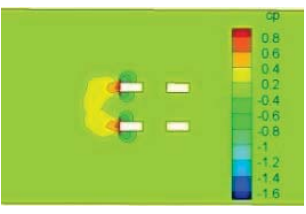

$\mathrm{z} / \mathrm{h}=0.84$

c) $\operatorname{Re}=131597$

Fig. (8): Pressure coefficient $\left(C_{p}\right)$ contours at different heights $\left(\theta=0^{o}\right)$. 
Upwind left model upwind right model

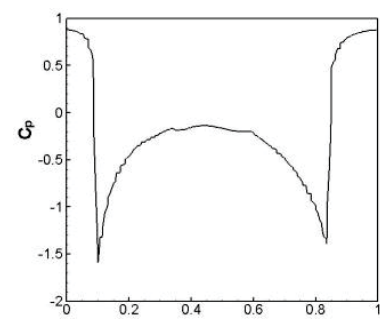

$\mathrm{s} / \mathrm{L}_{\mathrm{h}}$
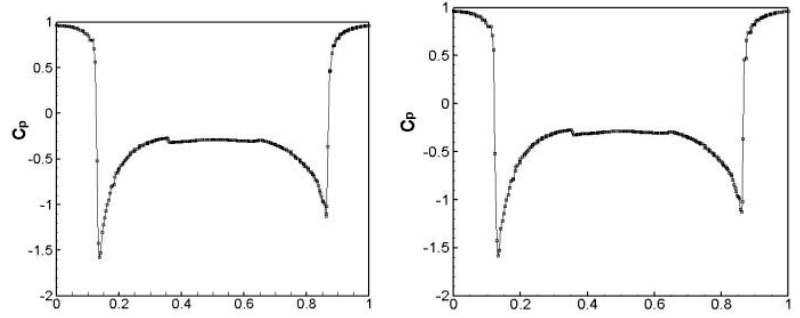

b) $\operatorname{Re}=65799$

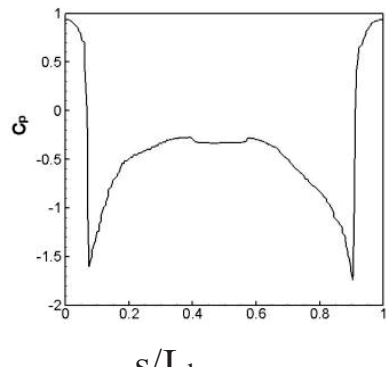

$\mathrm{s} / \mathrm{L}_{\mathrm{h}}$

c) $\operatorname{Re}=13159$

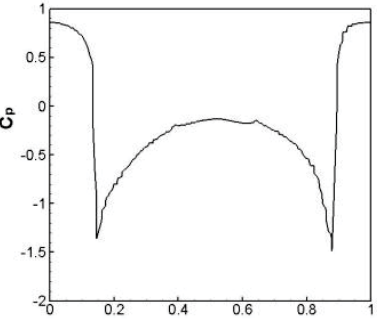

$\mathrm{s} / \mathrm{L}_{\mathrm{h}}$

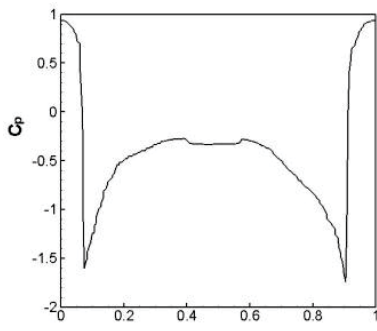

$\mathrm{s} / \mathrm{L}_{\mathrm{h}}$

Fig. (9): Pressure coefficient $\left(C_{p}\right)$ distribution at mid horizontal plane $\left(\theta=0^{o}\right)$.

\subsubsection{Wind direction angle $=90^{\circ}$ (Perpendicular to roof crest line)}

Figure (12a and b) shows the pressure coefficients contours at the mid vertical section, $(\mathrm{Re}=65799)$ for LHS and RHS buildings (w.r.t wind direction).The figure shows symmetry of flow configuration for LHS and RHS buildings. Also the stagnation point at approximately $86 \%$ of the building height, (this is where the highest wind force occurs). Fig. (13a and b)shows the distribution of the pressure coefficient along the mid vertical plane $\left(\mathrm{C}_{\mathrm{p}}-\right.$ $\mathrm{z} / \mathrm{L}_{\mathrm{v}}$ ),starting from the lowest point on leeward wall to the same point on the windward wall along the vertical plane, for the two front and back (right and left) building models at $\mathrm{Re}=65799$. The graphs show the symmetry of flow, the maximum value of pressure for back 
Upwind left model upwind right model

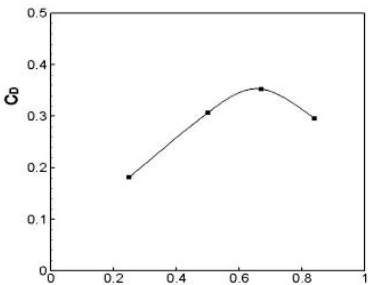

$\mathrm{z} / \mathrm{h}$

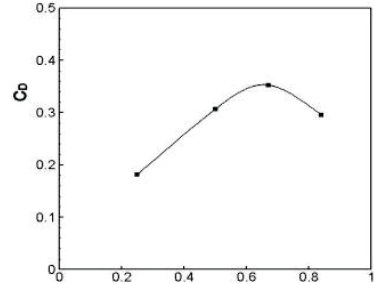

$\mathrm{z} / \mathrm{h}$ a) $\operatorname{Re}=46059$

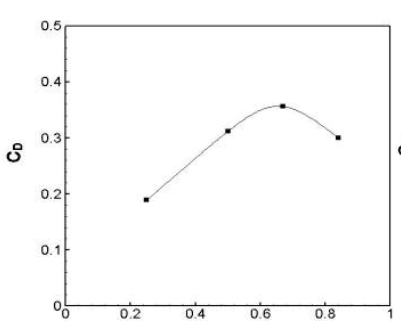

$\mathrm{z} / \mathrm{h}$
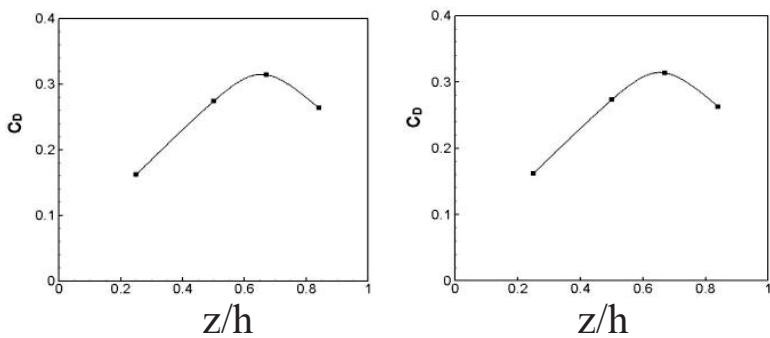

c) $\operatorname{Re}=131597$

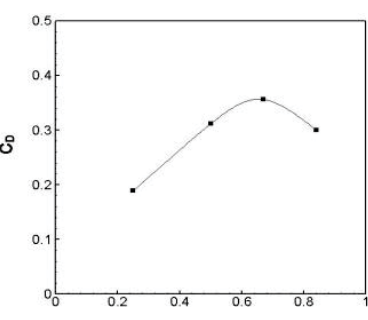

$\mathrm{z} / \mathrm{h}$ b) $\operatorname{Re}=65799$

Fig. (10): Local drag coefficient $\left(C_{D}\right)$ at mid horizontal plane.

and front (left and right) buildings is at $\mathrm{z} / \mathrm{L}_{\mathrm{v}}=0.43,0.25$ respectively and the minimum value of pressure for back and front (left and right) buildings is at $z / \mathrm{L}_{v}=0.5$. Figure ( $14 \mathrm{a}$ and $\mathrm{b}$ ) shows the streamline patterns at the mid vertical plane and $\operatorname{Re}$ no. $=65799$ for both left and right buildings. It is found from the symmetry between left and right buildings that a large scale of recirculation on the leeward pitch roof back building, also the back buildings always lie in the wake region of the front buildings.

\subsection{Experimental Results}

Figure (15) shows experimentally-obtained pressure coefficient contours for one of the front building models at $\mathrm{Re}=65799$. It is noticed that the highest pressure force is at approximately $86 \%$ of the building height. By the comparison with Fig. (7), we notice fair agreement in spite of the different in Re number.

Fig. (16) shows a comparison between the experimental and numerical results for the pressure coefficient distribution for the front building at $0^{\circ}$ wind direction angle and $\mathrm{Re}=65799$, showing a fairly good agreement.

Figure (17) shows flow lines visualized in the smoke tunnel for the four models together at $\theta=0^{\circ}$ and $\theta=90^{\circ}$, respectively. Symmetry property in flow is observed in both cases. 
Air flow
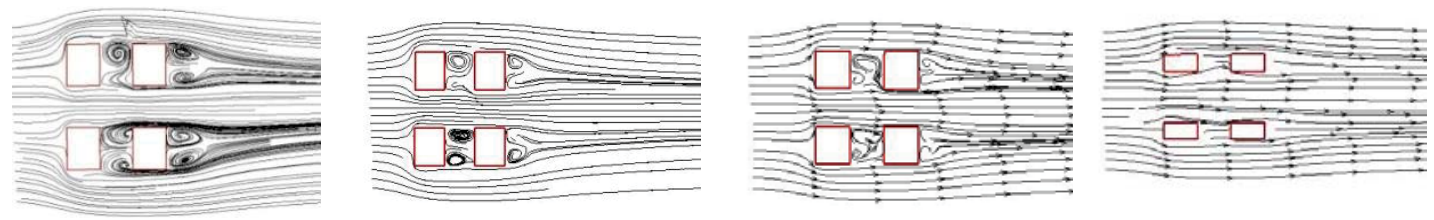

$\mathrm{z} / \mathrm{h}=0.25$

$\mathrm{z} / \mathrm{h}=0.5$

$\mathrm{z} / \mathrm{h}=0.67$

$\mathrm{z} / \mathrm{h}=0.84$

a) $\mathrm{Re}=46059$
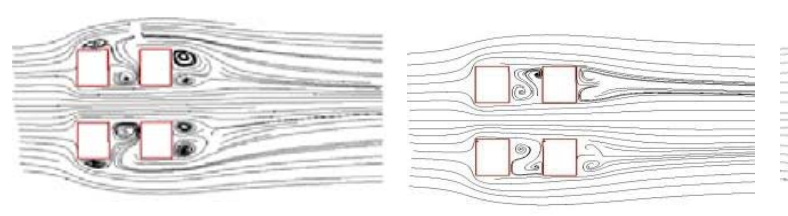

$$
\mathrm{z} / \mathrm{h}=0.25 \quad \mathrm{z} / \mathrm{h}=0 . \mathrm{J}
$$

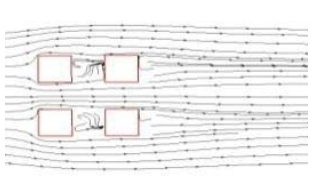

$\mathrm{z} / \mathrm{h}=0.67$

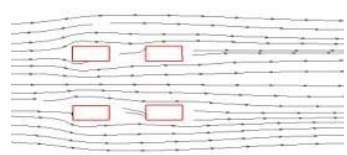

$\mathrm{z} / \mathrm{h}=\mathrm{U} . \mathrm{84}$

b) $\operatorname{Re}=65799$

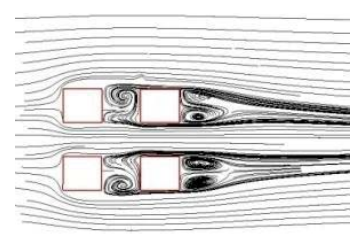

$\mathrm{z} / \mathrm{h}=0.25$

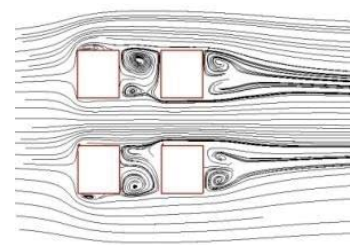

$\mathrm{z} / \mathrm{h}=0.5$

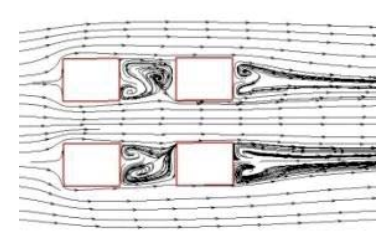

$\mathrm{z} / \mathrm{h}=0.67$

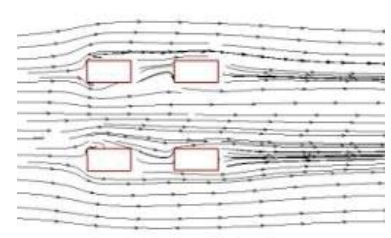

$\mathrm{z} / \mathrm{h}=0.84$

c) $\operatorname{Re}=131597$

Fig. (11): Streamline patterns at different heights.

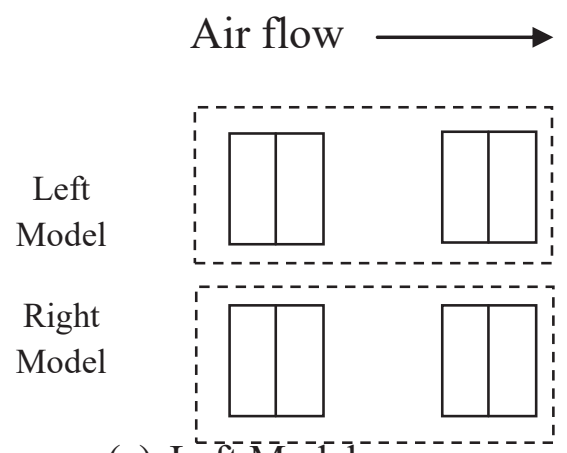

(a) Left Models

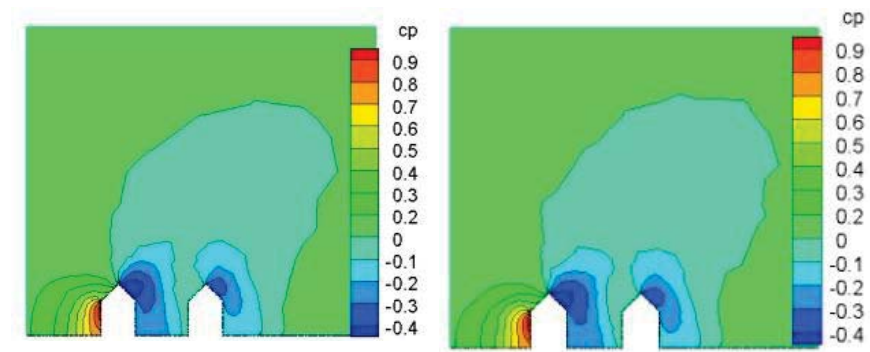

(b) Right Models

Fig. (12): Pressure contours $C p$ at mid vertical plane, $\operatorname{Re}=65799, \theta=90^{\circ}$. 


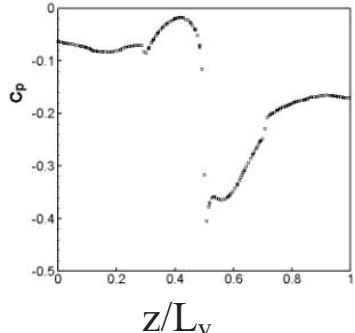

Back Left

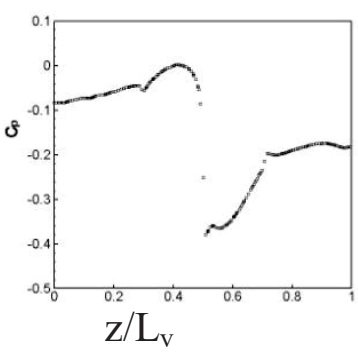

Back Right

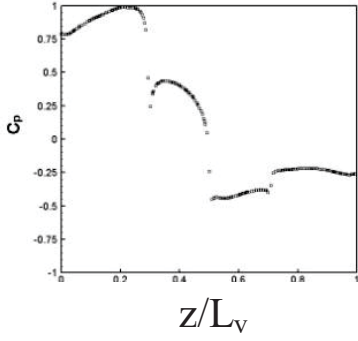

Front Left

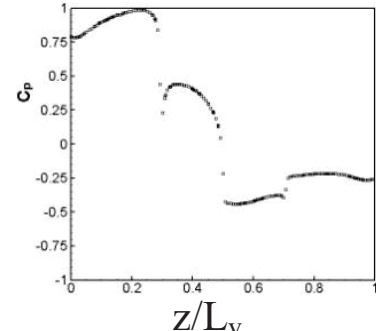

Front Right

(a)

(b)

Fig. (13): Distribution of pressure coefficient $C_{p}$ along the mid vertical plane $\left(\mathrm{C}_{\mathrm{p}}-\mathrm{z} / \mathrm{L}_{\mathrm{v}}\right.$ relation $), \boldsymbol{\theta}=90^{\circ}$.

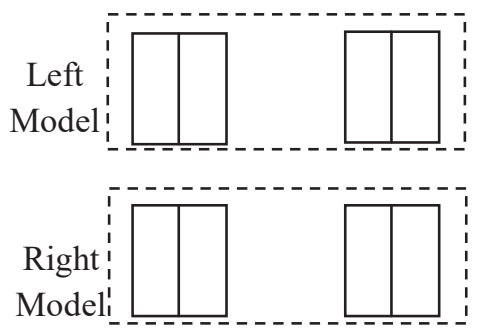

(a) Left Models
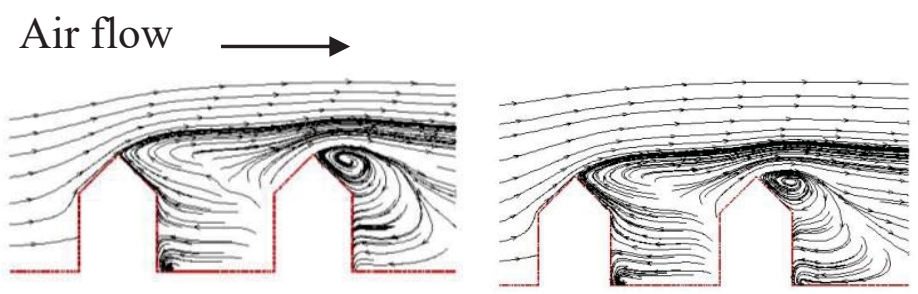

(b) Right Models

Fig. (14): Streamline patterns at the mid height plane, $\operatorname{Re}=65799,\left(\theta=90^{\circ}\right)$ air flow direction.

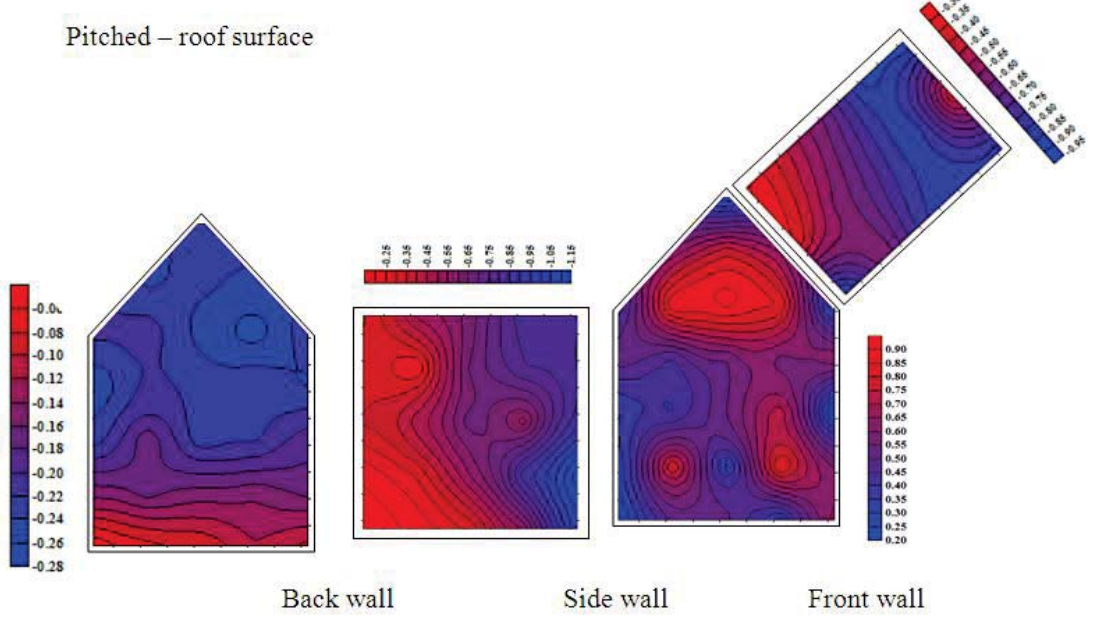

Fig. (15): Experimental $C_{p}$ contours of upwind model, $\operatorname{Re}=65799, \Theta=0^{\circ}$ (Surfer code using). 


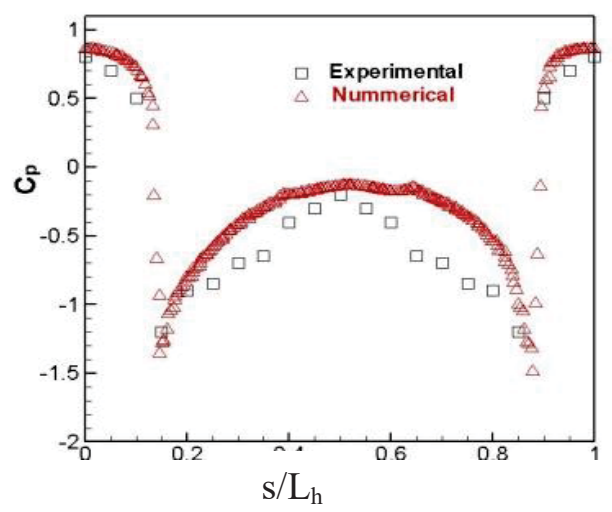

Fig. (16): Comparison between experimental and numerical $c_{p}$ results For Upwind Model $\left(\Theta=0^{\circ}, \operatorname{Re}=65799\right)$.

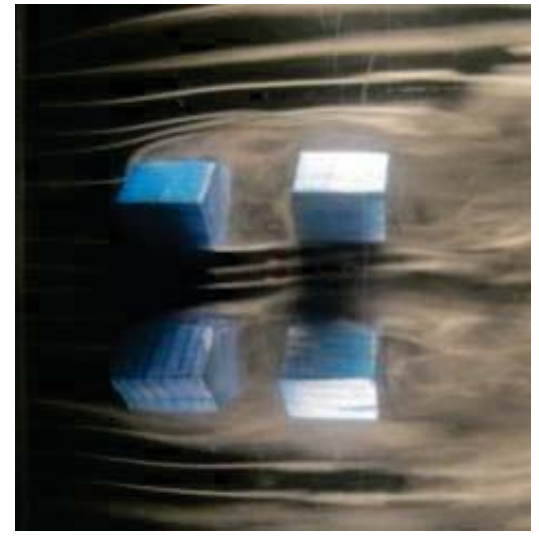

(a) $\Theta=0^{\circ}$

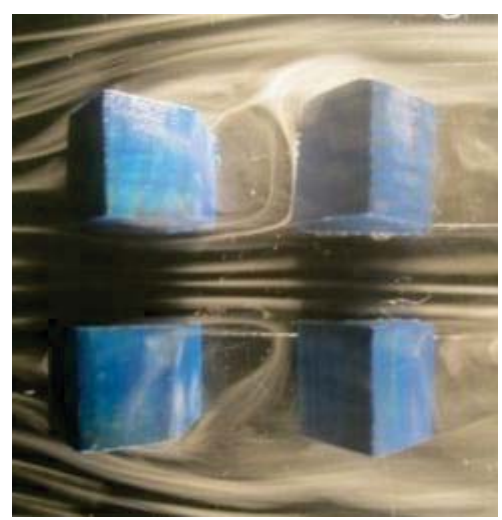

(b) $\Theta=90^{\circ}$

Fig. (17): Flow visualization for the four buildings at $0^{\circ}$ and $90^{\circ}$ angles.

\section{CONCLUSIONS}

(i) Results obtained by the present study show that the 3-D analysis using k-e model for four identical pitched- roof low-rise buildings agree fairly with wind tunnel results.

(ii) Pressure and drag coefficients, hence the wind force for the cases studied, reach their highest values (corresponding to stagnation) 
at $0.86,0.98$ of the height of the upwind and downwind building models, respectively.

(iii) Variation in values of wake length is found to occur for the downwind models depending on the flow angle of attack.

\section{REFERENCES}

1. Anne D. Cope, Kurtis R. Gurley, Massimiliano Gioffre, Timothy A. Low- rise gable roof wind loads: Characterization and stochastic simulation. Journal of Wind Engineering and Industrial Aerodynamics, Vol. 93, pp: 719-738, 2005.

2. Zaheer I., S. Ahmad, M. Muzzammil, Numerical predication of wind loads on low buildings. International journal of Engineering Science and Technology, Vol.3, No.5, pp: 59-72, 2011.

3. Lakehal, D. and Rodi, W., Calculation of the flow past a surface-mounted cube with two-layer turbulence models. Journal of Wind Engineering and Industrial Aerodynamics, Vol.67-68, pp: 65-78, 1997.

4. Murakami, S., Mochide, A. and Sokamoto, S .CFD analysis of windstructure interaction for oscillating square cylinders. Journal of Wind Engineering and Industrial Aerodynamics, Vol. 72, pp: 33-46, 1997.

5. Murakami, S., Iizuka, S. and Ooka, R. CFD analysis of turbulent flow past square cylinder using dynamic LES. Journal of fluids and structures, vol. 13, No: 7-8, pp: 1097-1112, 1999.

6. Nozawa, K. and Tamura, T., Large eddy simulation of the flow around a low-rise building immersed in a rough-wall turbulent boundary layer. Journal of Wind Engineering and Industrial Aerodynamics, Vol. 90, No: 10, pp: 1151-1162, 2002.

7. Gao, Y., and Chow, W.K. Numerical studies on air flow around a cube. Journal of Wind Engineering and Industrial Aerodynamics, Vol.93, No: 2, pp: 115-135, 2005 .

8. Huang, s., Li, Q. S. and Xu, S., Numerical evaluation of wind effects on a tall steel building by CFD, Journal of Constructional Steel Research. Vol. 63, No: 5, pp: 612-627, 2007.

9. Wael, M. E. Computational and experimental investigation of the characteristics of the wind loads acting on 
uncommon tall buildings, M.Sc. thesis, Zagazig University, Zagazig, Egypt, 2009.

10. J. D. Ginger and J. D. Holmes. Effect of building length on wind loads on low- rise buildings with a steep roof pitch, Journal of Wind Engineering and Industrial Aerodynamics, Vol. 91, pp: 1377-1400, 2003.

11. Kopp, G. Wind Loads on Low- Profile, Tilted, Solar Arrays Placed on Large, Flat, Low- Rise Building Roofs, Journal of Structural Engineering, Vol. 140, Issue 2, 2014.

\section{NOMENCLATURE}

$\mathrm{u}, \mathrm{v}, \mathrm{w}$ : Velocity-components in $\mathrm{x}, \mathrm{y}$ and $\mathrm{z}$ directions, $\mathrm{m} / \mathrm{s}$.

$\rho$ : Density of fluid, $\mathrm{kg} / \mathrm{m}^{3}$.

$\mu$ : Dynamic viscosity, Pa s.

$\mu_{\mathrm{t}}$ : Turbulent or Eddy viscosity, Pa s.

$\mathrm{K}$ : Turbulent kinetic energy, $\mathrm{m}^{2} / \mathrm{s}^{2}$.

C: Dissipation rate of turbulence, $\mathrm{m}^{2} / \mathrm{s}^{3}$.

$\sigma$ : Viscous stress tensor, $\mathrm{N} / \mathrm{m}^{2}$.

$\delta_{\mathrm{ij}}$ : Constant equal to 1 when $\mathrm{i}=\mathrm{j}$ and equal to zero when $\mathrm{i} \neq \mathrm{j}$. 